\title{
PARENTAL POSITIVE MEANING-MAKING WHEN CAREGIVING FOR CHILDREN WITH ASTHMA
}

\author{
Neuza Silva ${ }^{1}=$, Carlos Carona ${ }^{1,2}$ Carla Crespo ${ }^{1} \&$ Maria Cristina Canavarro ${ }^{1}$ \\ 1 Faculdade de Psicologia e Ciências da Educação da Universidade de Coimbra, Coimbra, Portugal; \\ 2 Associação de Paralisia Cerebral de Coimbra, Coimbra, Portugal.
}

\begin{abstract}
Providing informal care to children/adolescents with chronic conditions has been associated with high levels of caregiving burden and impaired quality of life (QoL); however, parents can also experience uplifts which, by facilitating the attribution of positive meanings to caregiving, may contribute to better adaptation outcomes. The present study aimed at examining the direct and indirect links, via positive reframing as a coping strategy, between caregiving uplifts and quality of life (QoL) of parents who have a child/adolescent with asthma, as well as the invariance of the mediation model across children's age groups and asthma severity levels. A total of 180 parents of children/adolescents aged 8-18 reported their experience of caregiving uplifts (Revised Burden Measure), the use of positive reframing coping (Brief Cope) and their QoL (WHOQOL-Bref). Structural equation modeling showed a good fit for the mediation model $\left(\chi^{2} / d f=1.74, C F I=.95, R M S E A=.06\right)$, which explained $14 \%$ of the variability of parents' QoL. The caregiving uplifts were positively associated with positive reframing coping $(\beta=.19, p=.02)$, which in turn was positively associated with QoL $(\beta=.36, p<.01)$. No direct effect of uplifts on parents' QoL was found, but the indirect effect via positive reframing coping was statistically significant $(\beta=.07, \mathrm{BC} 95 \% \mathrm{CI}=.01 / .14)$. Multi-group analyses demonstrated the strong structural invariance of the model across age groups $\left(\Delta \chi^{2}=.89\right.$, $p=.35)$ and asthma severity levels $\left(\Delta \chi^{2}=1.91, p=.17\right)$. These results suggest that psychological interventions focused on recognizing and valuing caregiving uplifts and on positive reappraisal of the stressful situation may support more adaptive coping processes and improve parents' QoL.

Keywords- Caregiving uplifts, Coping, Parents/ family caregivers, Pediatric asthma, Positive reframing, Quality of life
\end{abstract}

\section{SIGNIFICAÇÕES PARENTAIS POSITIVAS NA PRESTAÇÃO DE CUIDADOS A CRIANÇAS/ ADOLESCENTES COM ASMA}

RESUMO - A prestação de cuidados a crianças/adolescentes com condições crónicas tem sido associada a níveis elevados de desgaste e menor qualidade de vida $(\mathrm{QdV})$; no entanto, os pais podem também experienciar gratificações que, facilitando uma atribuição de

\footnotetext{
[: Faculdade de Psicologia e Ciências da Educação da Universidade de Coimbra, Rua do Colégio Novo, Apartado 6153, 3001-802 Coimbra, Portugal - Phone number: 239851450; Fax: 239851465. E-mail: neuzambsilva@gmail.com
} 
significados positivos à prestação de cuidados, podem contribuir para melhor adaptação. Este estudo pretendeu analisar as associações directas e indirectas, via reinterpretação positiva, entre as gratificações resultantes da prestação de cuidados e a QdV dos pais de crianças/adolescentes com asma, bem como a invariância destas associações entre grupos etários e níveis de gravidade da asma. Um total de 180 pais de crianças/adolescentes entre 8 e 18 anos reportaram as suas experiências de gratificação (Escala de Desgaste do Cuidador), o recurso à reinterpretação positiva enquanto estratégia de coping (Brief Cope) e a sua QdV (WHOQOL-Bref). Análises de equações estruturais mostraram um bom ajustamento do modelo de mediação $\left(\chi^{2} / g l=1,74 ; C F I=0,95 ; R M S E A=0,06\right)$, que explicou $14 \%$ da variabilidade da $\mathrm{QdV}$ dos pais. As gratificações associaram-se positivamente à reinterpretação positiva $(\beta=0,19 ; p=0,02)$, que por sua vez se associou com a $\mathrm{QdV}(\beta=0,36$, $p<0,01)$. Não foi encontrado efeito directo das gratificações na $\mathrm{QdV}$, mas o efeito indirecto via reinterpretação positiva foi estatisticamente significativo $(\beta=0,07$; $\mathrm{BC} 95 \% \mathrm{CI}=0,01 / 0,14)$. Análises multigrupos demonstraram a invariância do modelo estrutural entre grupos etários $\left(\Delta \chi^{2}=0,89 ; p=0,35\right)$ e níveis de gravidade da asma $\left(\Delta \chi^{2}=1,91\right.$; $p=0,17)$. Estes resultados sugerem que intervenções psicológicas focadas no reconhecimento e valorização das gratificações e na reavaliação positiva da prestação de cuidados podem promover processos de coping mais adaptativos e melhorar a QdV dos pais.

Palavras-chave- Asma pediátrica, Coping, Gratificação na prestação de cuidados, Pais/ cuidadores familiares, Qualidade de vida, Reinterpretação positiva

Recebido em 9 de Dezembro de 2013/ Aceite em 20 de Março de 2014

Parental caregiving for children with chronic health conditions is a complex experience, encompassing both negative and positive dimensions, such as caregiving burdens and uplifts (Green, 2007; Larson, 2010). While the deleterious effects of caregiving burden on parents' adaptation outcomes are documented in pediatric literature for chronic medical conditions in general (Canning, Harris, \& Kelleher, 1996), and for asthma in particular (Crespo, Carona, Silva, Canavarro, \& Dattilio, 2011; Fiese, Wamboldt, \& Anbar, 2005), the associations between caregiving uplifts and adaptation outcomes remain a neglected research topic. Even if some authors have suggested a positive impact of perceived benefits of caregiving on parents' emotional and physical health (Green, 2007), and some evidence has been gathered for the buffering effect of caregiving uplifts on the associations between caregiving burden and parents' quality of life (QoL) when caring for a child with a disability (Carona, Pereira, Moreira, Silva, \& Canavarro, 2013), the examination of the role of positive coping strategies on these parental adaptation processes has not been yet conducted. The study of potential positive coping mechanisms in the context of pediatric conditions, namely asthma, can improve parental adaptation outcomes through a better understanding of specific modifiable variables and mechanisms to be targeted in intervention processes. This study could, thus, contribute to refine the current operationalization of a strength-based approach to family interventions in pediatric settings (Beresford, 1994).

Despite the consensual claim that parents caring for a child with a chronic health condition face considerable stress and caregiving demands, a transition from deficit-based models to a 
risk-resilience framework has been increasingly acknowledged as a mean of enabling a more comprehensive understanding on the diversity of trajectories related to parental stress, coping and adaptation processes in those situations (Beresford, 1994). In the disability-stress-coping model, a risk-resilience framework on individual and family adaptation to chronic physical conditions, stress processing variables, such as cognitive appraisal and coping strategies, are assumed as resistance factors that increase the likelihood of positive adaptation outcomes, including positive mental health, social functioning and physical health (Wallander, Varni, Babani, Banis, \& Wilcox, 1989). Since common criticisms to psychosocial research on parental adaptation to pediatric conditions include the disregard of positive dimensions related to adaptation processes (Barlow \& Ellard, 2006), the study of positive dimensions of parental caregiving and coping seems imperative to support family-centered pediatric interventions, which are essentially aimed at targeting "existing family strengths and capabilities so that interventions are built on things a particular family already does well" (Judge, 1998, p. 263).

Interestingly, the observation that positive and negative psychological states may co-occur during caregiving processes, has led researchers to explore the role of positive emotion in disposing individuals to appraise stressful situations more as a challenge than as a threat (Folkman, 1997; Folkman \& Moskowitz, 2000). The experience of positive emotions and psychological states during stressful situations is related to the adoption of meaning-based coping (e.g., positive reappraisal), and hypothesized to sustain adaptive coping processes (Folkman, 1997). Meaning-making is a cognitive coping process based on the reinterpretation of stressful events to minimize distress, and may occur at the global (e.g., reprioritization of family goals) or situational levels (e.g., benefit finding and personal growth) (Larson, 2010). In the specific case of pediatric asthma, it has been considered that families face considerable stress and demands, such as worry, restrictions of daily activities and interference with family routines, aside with the development of alternative, optimistic coping strategies that may serve as buffers from stress (Garro, 2011).

Although some authors commented on the relationship of positive caregiving perceptions with increased subjective well-being (Larson, 2010) and greater psychological flexibility (Gupta \& Singhal, 2004), such tenets remain empirically unexamined, particularly for family caregiving in the context of pediatric conditions. In a recent study, the experience of uplifts tended to be more frequent in parents of children when compared to parents of adolescents in both groups of parents who had a child with a disability or a typically developing child, and caregiving uplifts were linked to the psychosocial QoL outcomes of parents of a child with a disability (Carona, Pereira, et al., 2013). The experience of caregiving uplifts has been also observed for parents of children with asthma, who tended to acknowledge positive gain from caregiving, such as personal growth from assuming a caregiver role (Gates \& Akabas, 2012). Nevertheless, even with promising data on the beneficial effects of caregiving uplifts on parental adaptation, the mechanisms underlying these pathways have not been ascertained.

As proposed by the broaden-and-build model, the experience of positive emotions broadens the individual's scope of attention (e.g., mindful attention focus), cognition (e.g., creative thinking) and action (e.g., behavioral variety), which ultimately promote the development of his/her physical (e.g., vitality), intellectual (e.g., psychological flexibility) and social (e.g., pro-social mentality) resources (Frederickson, 1998). Assuming family caregiving for a child with asthma as a significant developmental context, one can hypothesize that 
caregiving uplifts may improve parental adaptation outcomes through the development of positive dispositional coping tendencies. In line with the aforementioned stress and coping models, one of those coping tendencies is positive reframing or reappraisal, a dispositional, emotion-focused coping strategy, which has been defined as changing the situation's meaning by focusing on the good aspects of what has happened or what is happening (Carver, 1997; Carver, Scheier, \& Weintraub, 1989; Folkman \& Moskowitz, 2000).

In the present study, caregiving uplifts were assumed as positive emotions and gratifications arising from caring for a child with a chronic health condition, and QoL was understood as an overall parental adaptation outcome within the developmental context of family caregiving. The main objective of this study was to examine the direct and indirect associations, via positive reframing coping, between caregiving uplifts and QoL outcomes of parents caring for a child with asthma. Accordingly, it was hypothesized that the experience of more caregiving uplifts would be associated with parents' better QoL, and that positive reframing coping would mediate that link. We also tested the invariance of the mediation model across children's age groups and asthma severity levels, but no specific predictions were made on this regard.

\section{Participants}

\section{METHOD}

A total of 110 parents of children with asthma aged 8-12 years and 70 parents of adolescents with asthma aged 13-18 years were included in the sample. Descriptive statistics for parents' and their children's socio-demographic and clinical variables are displayed in Table 1.

Table 1

Socio-demographic and Clinical Characteristics of the Sample $(N=180)$

\begin{tabular}{|c|c|c|c|}
\hline & $\begin{array}{l}\text { Parents of children } \\
(n=110)\end{array}$ & $\begin{array}{c}\text { Parents of } \\
\text { adolescents }(n=70)\end{array}$ & $\begin{array}{c}\text { Differences } \\
\text { between groups }\end{array}$ \\
\hline \multicolumn{4}{|c|}{ Parents' socio-demographic characteristics } \\
\hline Age (in years), $M(S D)$ & $39.83(6.06)$ & $42.96(4.71)$ & $t=-3.65^{88}$ \\
\hline \multicolumn{4}{|l|}{ Gender, $n(\%)$} \\
\hline Male & $15(3.6 \%)$ & $13(18.6 \%)$ & \multirow{2}{*}{$\chi^{2}=.79$} \\
\hline Female & $95(86.4 \%)$ & $57(81.4 \%)$ & \\
\hline \multicolumn{4}{|c|}{ Socio-economic status, $n(\%)$} \\
\hline Low & $60(54.5 \%)$ & $46(65.7 \%)$ & \multirow{3}{*}{$\chi^{2}=1.77$} \\
\hline Medium/ high & $46(41.8 \%)$ & $23(32.9 \%)$ & \\
\hline Missing & $4(3.6 \%)$ & $1(1.4 \%)$ & \\
\hline \multicolumn{4}{|c|}{ Children's socio-demographic characteristics } \\
\hline Age (in years), $M(S D)$ & $10.24(1.26)$ & $14.71(1.49)$ & - \\
\hline \multicolumn{4}{|l|}{ Gender, $n(\%)$} \\
\hline Male & $77(70.0 \%)$ & $39(55.7 \%)$ & \multirow{2}{*}{$\chi^{2}=3.81^{*}$} \\
\hline Female & $33(30.0 \%)$ & $31(44.3 \%)$ & \\
\hline \multicolumn{4}{|l|}{ Clinical characteristics } \\
\hline \multicolumn{4}{|l|}{ Asthma severity, $n(\%)$} \\
\hline Intermittent & $56(50.9 \%)$ & $39(55.7 \%)$ & \multirow{4}{*}{$\chi^{2}=1.46$} \\
\hline Mild persistent & $35(31.8 \%)$ & $17(24.3 \%)$ & \\
\hline Moderate persistent & $15(13.6 \%)$ & $12(17.1 \%)$ & \\
\hline Severe persistent & $4(3.6 \%)$ & $2(2.9 \%)$ & \\
\hline Age at diagnosis, $M(S D)$ & $4.25(2.86)$ & $5.25(4.68)$ & $t=-1.59$ \\
\hline Disease length, $M(S D)$ & $6.05(2.96)$ & $9.47(4.41)$ & $t=-5.66^{* 8}$ \\
\hline
\end{tabular}


Comparison tests of socio-demographic and clinical characteristics (independent samples $t$ tests for continuous variables and chi-square tests for categorical variables) between parents of children aged 8-12 years and parents of adolescents aged 13-18 years showed no significant differences regarding parents' gender, socio-economic status, asthma severity levels and child's age at the time of asthma diagnosis. However, the group of parents of adolescents was significantly older, had a higher portion of daughters and had lived with the child's condition for a longer time when compared with the group of parents of children.

\section{Materials}

Caregiving uplifts - The parents' experience of gratification and positive psychological states arising from caregiving, such as the direct enjoyment from caregiving tasks, an improved relationship with their child, and generalized positive affect, was assessed with the Uplifts subscale of the Revised Burden Measure (Montgomery \& Kosloski, 2006; Portuguese version: Carona, Silva, \& Canavarro, 2011). This subscale comprises six items (e.g., "Have your caregiving responsibilities given your life more meaning?"), which were answered in a 5-point Likert scale, ranging from 1 (Not at all) to 5 (A great deal). Higher scores indicate the experience of more caregiving uplifts. In our sample, the Uplifts subscale presented good reliability, with a Cronbach's alpha value of .85. For the structural equation modeling, the six items were considered observed indicators, which loaded on a latent variable of caregiving uplifts (factor loadings and composite reliability for the latent variable are presented in Table $3)$.

Positive reframing - The parents' use of positive reframing as a dispositional coping strategy was evaluated with the Positive Reframing subscale of the Portuguese brief version of the Cope inventory (Carver, 1997; Portuguese version: Pais-Ribeiro \& Rodrigues, 2004). This subscale comprises two items assessing the parents' attempts to look at the stressful situation in a more beneficial way and grow from it ("I've been trying to see it in a different light, to make it seem more positive"; "I've been looking for something good in what is happening"). The answers were provided in a Likert-type response scale with four options, ranging from 0 (I haven't been doing this at all) to 3 (I've been doing this a lot), with higher scores indicating more frequent use of the coping strategy. In our sample, the positive reframing coping subscale proved to have adequate reliability, with a Cronbach's alpha value of .70. A latent variable, comprising the two items as observed indicators, was designed for the analyses of structural equation models (factorial validity and composite reliability for the latent variable are presented in Table 3).

Quality of life - Parent's QoL was measured with the Portuguese brief version of the World Health Organization Quality of Life (WHOQOL) instrument (The WHOQOL Group, 1998; Portuguese version: Vaz-Serra, et al., 2006). This questionnaire comprised 26 items clustered into a generic facet ( 2 items; not used in the present study) and four QoL domains, namely Physical (7 items; e.g., "Do you have enough energy for everyday life?"), Psychological (6 items; e.g., "How often do you have negative feelings such as blue mood, despair, anxiety, depression?"), Social relationships (3 items; e.g., "How satisfied are you 
with the support you get from your friends?") and Environmental (8 items; e.g., "How satisfied are you with your access to health services?"). The items were answered using a 5point Likert scale addressing intensity (not at all to extremely), capacity (not at all to completely), frequency (never to always) or evaluation (very dissatisfied to very satisfied), with higher values indicating better QoL. All of the four QoL domains presented good reliability, with Cronbach's alpha values ranging from .74 (Social relationships domain) to .83 (Psychological domain). For the structural equation modeling we considered the four QoL domains as observed indicators loading on a latent variable of parents' QoL (factor loadings and composite reliability for the latent variable are presented in Table 3).

Sociodemographic and clinical variables - Asthma severity was classified by the child's physician into four categories (intermittent, mild persistent, moderate persistent and severe persistent), according to the Global Initiative for Asthma guidelines (GINA, 2008). Due to the low frequency of children/ adolescents in the persistent asthma levels, this variable was dichotomized and dummy-coded ( 0 - intermittent asthma, $n=95 ; 1$ - persistent asthma [mild, moderate, persistent], $n=85$ ). Other clinical data (e.g., age at the time of diagnosis) and sociodemographic information (e.g., parents' and their children's age and gender) was collected from parents. The socio-economic status (SES) was determined using a classification system for the Portuguese context, based on parents' job and educational level (Simões, 1994).

\section{Procedures}

The present study was approved by the Ethics Committee and/ or Direction Board of three Portuguese public hospitals (Coimbra University Hospitals, Coimbra Pediatric Hospital, and Leiria Santo André Hospital). The sample was collected in the Pediatric and Immunoallergology outpatient services of the aforementioned health institutions, between September 2010 and February 2012, using the non-probabilistic convenience sampling method. For inclusion in the sample, parents had to meet the following criteria: 1) having a child aged between 8 and 18 years, with clinical diagnosis of asthma established by a physician according to the International Classification of Diseases system (ICD-10) for at least one year, and with no comorbidities with other chronic health conditions or severe psychiatric disorders; and 2) being the parent who, at the time of assessment, assumed the primary caregiver role on child's health related issues. The study's aims and procedures were explained in detail and written informed consent forms were obtained from all of the parents who agreed to participate. The parents completed a set of self-reported questionnaires in an office assigned for research purposes, in the health institution that their child attended. A trained research assistant was available to provide support during the completion of the assessment protocol, whenever necessary.

Statistical analyses were conducted with SPSS (SPSS Inc., Chicago, IL, USA). Except for socio-demographic and clinical variables, missing data, that were random and low level (less than 5\%), were handled by individual mean score substitution. Descriptive statistics were calculated for socio-demographic, clinical and psychosocial variables and Pearson correlation coefficients among study variables were examined. 
Structural Equation Modeling (SEM) was performed with Analysis of Moments Structures (AMOS). The method of estimation was the maximum likelihood and the overall model fit was evaluated based on the chi-square statistic $\left(\chi^{2}\right)$ and on the main approximate goodness-offit indexes, namely the comparative fit index $(C F I)$, the root mean square error of approximation (RMSEA) and the standardized root mean squared residual (SRMR). A model was considered to have a good fit when $\chi^{2}$ was non-significant $(p>.05), C F I \geq .95, R M S E A \leq .06$ $(p>.05)$ and $S R M R \leq .08$, and an acceptable fit when $C F I \geq .90$ and $R M S E A \leq .10$ (Browne \& Cudeck, 1993; Hu \& Bentler, 1999). In the first step, to ensure the pertinence of multidimensional constructs (latent variables), we examined the measurement model by conducting a confirmatory factor analysis (CFA) testing the hypothesized links between the latent variables and their observed indicators. For each latent variable, the construct reliability was assessed by calculating composite reliability values, i.e., the ratio between the squared sum of standardized factor loading and the squared sum of standardized factor loading plus the sum of the error variance terms; good construct reliability was established if composite reliability value was higher than .70 (Hair, Black, Babin, \& Anderson, 2010). In the second step, we examined the structural model testing the direct and indirect effects, via positive reframing coping, of caregiving uplifts on parents' QoL. The statistical significance of the indirect effects was evaluated using bootstrap resampling procedures (Preacher \& Hayes, 2008; Williams \& MacKinnon, 2008), with 2000 samples and 95\% bias-corrected bootstrap confidence interval (BC 95\% CI).

The invariance of the mediation model across children's age groups and asthma severity levels was tested in two steps: first we examined the baseline model for each group separately, and, subsequently, we conducted multi-group analyses comparing the unconstrained model with models in which measurement weights, measurement intercepts, structural weights and structural covariances were sequentially and cumulative fixed to be equal across groups. Strong structural invariance was established when the chi-square difference between models $\left(\Delta \chi^{2}\right)$ was non-significant (Little, 2013).

\section{RESULTS}

\section{Descriptive Statistics and Inter-correlations among Study Variables}

Descriptive statistics and correlations among study variables are presented in Table 2. Higher levels of caregiving uplifts were associated with more frequent use of positive reframing as a coping strategy and with better QoL in the social relationships domain. Moreover, positive reframing was positively associated with all dimensions of parents' QoL. Regarding socio-demographic and clinical variables, no significant associations with caregiving uplifts, positive reframing or parents' QoL were found, except for marginally significant association between children' age and caregiving uplifts $(p=.06)$; children' age and positive reframing $(p=.07)$; and asthma severity and parents' social QoL $(p=.06)$. 
Table 2

Descriptive Statistics and Matrix of Inter-correlations among Study Variables

\begin{tabular}{lcccccc}
\hline Psychosocial variables & 1 & 2 & 3 & 4 & 5 & 6 \\
\hline 1. Caregiving uplifts & - & & & & & \\
2. Positive reframing & $.16^{*}$ & - & & & & \\
3. Physical QoL & .05 & $.17^{*}$ & - & & & \\
4. Psychological QoL & .10 & $.22^{* 8}$ & $.57^{* 8}$ & - & & \\
5. Social QoL & $.16^{*}$ & $.34^{* 8}$ & $.41^{* 8}$ & $.68^{* 8}$ & - & \\
6. Environmental QoL & .12 & $.17^{*}$ & $.54^{* 8}$ & $.63^{* 8}$ & $.55^{* 8}$ & - \\
\hline Socio-demographic and clinical variables & & & & \\
Children's age & $-.14^{\dagger}$ & $.13^{\dagger}$ & .12 & .07 & .01 & .11 \\
Asthma severity & -.01 & .08 & .05 & .05 & $.14^{\dagger}$ & .06 \\
\hline Mean & 3.06 & 2.00 & 3.90 & 3.86 & 3.95 & 3.62 \\
(SD) & $(0.99)$ & $(0.71)$ & $(0.58)$ & $(0.60)$ & $(0.66)$ & $(0.54)$ \\
Cronbach's alpha & .85 & .70 & .81 & .83 & .74 & .82 \\
\hline
\end{tabular}

${ }^{8 *} p \leq .01 ;{ }^{*} p \leq .05,{ }^{\dagger} p<10$, two-tailed.

\section{The Measurement Model}

The measurement model (CFA) testing the hypothesized links between the latent variables (caregiving uplifts, positive reframing and parents' QoL) and their observed indicators had a good fit, with $\chi_{(52)}^{2}=90.55, p<.01 ; C F I=.95 ; R M S E A=.06 \quad(p=.14 ; 90 \% \mathrm{CI}=.04 / .09)$; and $S R M R=.06$. As presented in Table 3, all of the observed indicators had standardized regression weights above the threshold of .50 and were statistically significant. In addition, the latent variables presented adequate construct reliability, with composite reliability values above .70. Except for the item PR2, the squared multiple correlations $\left(R_{\text {smc }}^{2}\right)$ between each observed indicator and all other observed indicators were lower than .90 and the tolerance values $\left(1-R_{\text {smc }}^{2}\right.$ ) were higher than .10 (Table 3 ), indicating that each one of the observed variables explained a substantial proportion of the total standardized variance (Kline, 2005).

Table 3

Multicollinearity Diagnosis, Factor Loadings of Observed Indicators and Composite

Reliability for Latent Variables

\begin{tabular}{|c|c|c|c|c|c|}
\hline Latent variable & $\begin{array}{l}\text { Observed } \\
\text { indicators }\end{array}$ & $R_{\text {smc }}^{2}$ & $\begin{array}{l}\text { Tolerance } \\
\left(1-R^{2}{ }_{\text {smc }}\right)\end{array}$ & $\begin{array}{c}\text { Factor } \\
\text { loadings }\end{array}$ & $\begin{array}{l}\text { Composite } \\
\text { reliability }\end{array}$ \\
\hline \multirow[t]{6}{*}{ Caregiving uplifts } & Item U1 & .44 & .56 & $.66^{88}$ & .85 \\
\hline & Item U2 & .48 & .52 & $.69^{* *}$ & \\
\hline & Item U3 & 49 & .51 & $.70^{88}$ & \\
\hline & Item U4 & .53 & .47 & $.73^{* 8}$ & \\
\hline & Item U5 & .49 & .51 & $.70^{* *}$ & \\
\hline & Item U6 & .56 & .44 & $.75^{* *}$ & \\
\hline \multirow{2}{*}{ Positive reframing } & Item PR1 & .30 & .70 & $.55^{88}$ & .77 \\
\hline & Item PR2 & .99 & .01 & $.99^{* 8}$ & \\
\hline \multirow[t]{4}{*}{ Parents' QoL } & Physical & .41 & .59 & $.64^{88}$ & .84 \\
\hline & Psychological & .76 & .24 & $.87^{* 8}$ & \\
\hline & Social & .58 & .42 & $.76^{88}$ & \\
\hline & Environmental & .54 & .46 & $.74^{* 8}$ & \\
\hline
\end{tabular}

${ }^{8 *} p \leq .01 ;{ }^{*} p \leq .05$, two-tailed. 


\section{The Structural Model}

After confirming the adequacy of the measurement model, a structural model testing the direct and indirect effects, via positive reframing coping, of caregiving uplifts on parents' QoL was tested. The model, which is displayed in Figure 1, had a good fit, with $\chi_{(52)}^{2}=90.55$, $p<.01 ; C F I=.95 ; R M S E A=.06$ ( $p=.14 ; 90 \% \mathrm{CI}=.04 / .09)$; and $S R M R=.06$, and explained $14 \%$ of the variability of parents' QoL. We found significant direct links between caregiving uplifts and positive reframing $(\beta=.19, p=.02)$ and between positive reframing and parents' QoL $(\beta=.36, p<.01)$. Although the direct effect of caregiving uplifts on parent's QoL was not statistically significant $(\beta=.08, p=.33)$, a significant indirect effect via positive reframing coping was found $(\beta=.07, p=.02 ; \mathrm{BC} 95 \% \mathrm{CI}=.01 / .14)$.

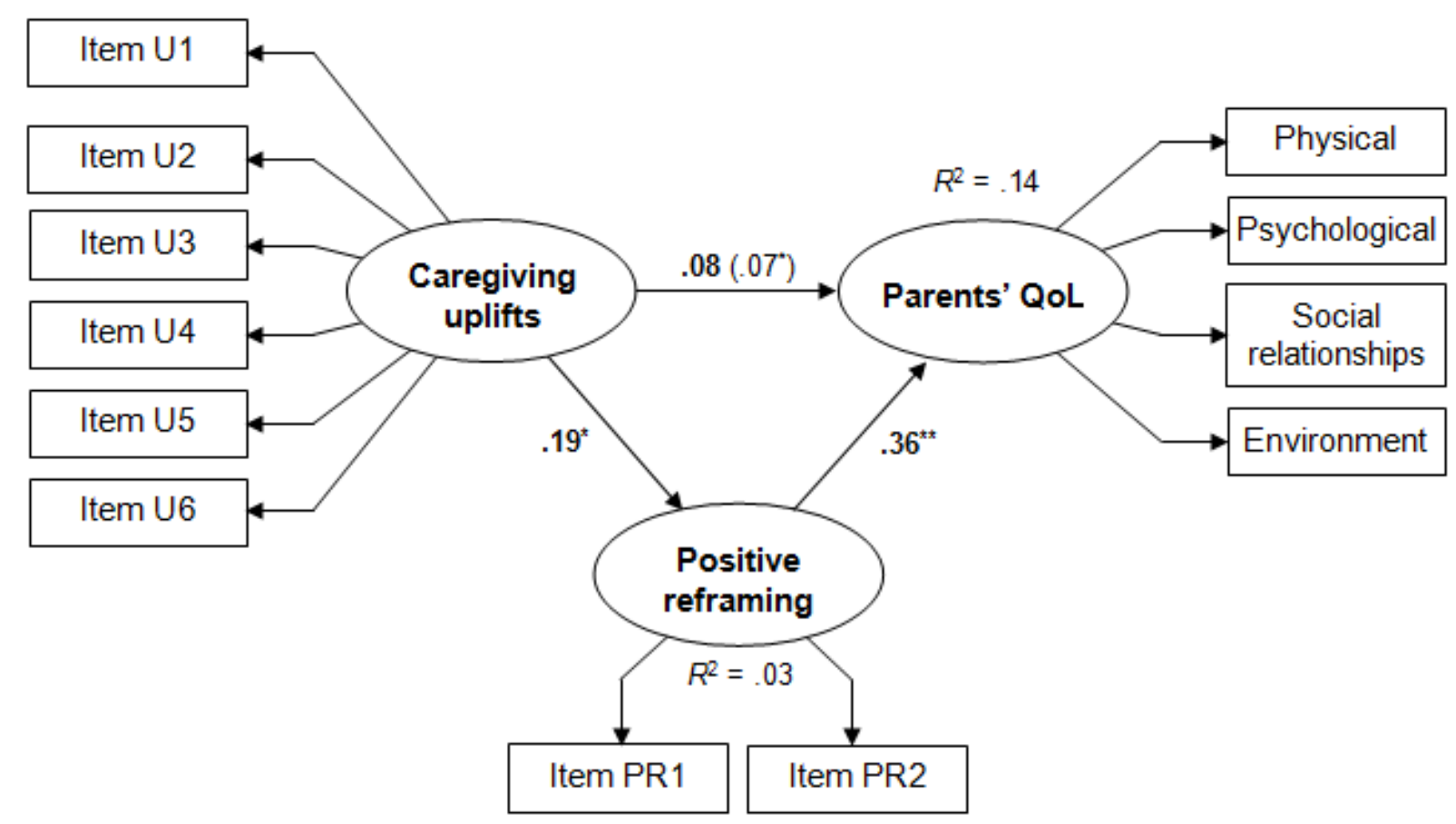

Figure 1. Structural equation model testing the direct and indirect effects, via positive reframing, of caregiving uplifts on parents' QoL. Bold figures represent standardized regression weights for direct paths; non-bold figures in brackets represent standardized regression weights for indirect paths. For simplicity, measurement error terms are not shown. ${ }^{*} p \leq .05 ;{ }^{*} p \leq .01$.

\section{Multi-group Analyses}

The examination of the baseline mediation model for children's age groups separately revealed that the model had a good fit for parents of children aged 8-12 and an acceptable fit for parents of adolescents aged 13-18 years-old (summary of fit statistics are presented in Table 4). Regarding asthma severity groups, the mediation model had an acceptable fit for both parents of children with intermittent asthma and parents of children with persistent 
asthma. As presented in Table 4, no significant differences between the unconstrained model and the models with fixed measurement weights, fixed measurement intercepts, fixed structural weights and fixed structural covariances were found, confirming that the parameters tested in the mediation model were similar for both children's age and asthma severity groups.

\begin{tabular}{|c|c|c|c|c|c|c|c|}
\hline & $x^{2}$ & $d f$ & $C F I$ & $\begin{array}{l}\text { RMSEA } \\
{[90 \% \mathrm{CI}]}\end{array}$ & SRMR & $\Delta \mathcal{\psi}^{2}$ & $\Delta d f$ \\
\hline \multicolumn{8}{|l|}{ Children's age groups } \\
\hline \multicolumn{6}{|l|}{ Summary of fit statistics } & & \\
\hline Adolescents 13-18 & $81.48^{* 8}$ & 52 & .92 & $.09[.05 / .13]$ & .09 & & \\
\hline \multicolumn{8}{|l|}{ Multi-group analyses } \\
\hline Unconstrained model & $153.85^{88}$ & 104 & .94 & $.05[.03 / .07]$ & .06 & - & - \\
\hline Measurement weights & $163.62^{88}$ & 113 & .94 & $.05[.03 / .07]$ & .06 & 9.77 & 9 \\
\hline Measurement intercepts & $182.14^{88}$ & 125 & .93 & $.05[.03 / .07]$ & .06 & 18.52 & 12 \\
\hline Structural weights & $182.75^{* 8}$ & 128 & .93 & $.05[.03 / .06]$ & .07 & 0.61 & 3 \\
\hline Structural covariances & $183.64^{88}$ & 129 & .93 & $.05[.03 / .06]$ & .07 & 0.89 & 1 \\
\hline \multicolumn{8}{|l|}{ Asthma severity groups } \\
\hline \multicolumn{8}{|l|}{ Summary of fit statistics } \\
\hline Intermittent asthma & $84.62^{88}$ & 52 & .93 & $.08[.05 / .11]$ & .08 & & \\
\hline Persistent asthma & $86.52^{8 *}$ & 52 & .91 & $.09[.05 / .12]^{*}$ & .07 & & \\
\hline \multicolumn{8}{|l|}{ Multi-group analyses } \\
\hline Unconstrained model & $171.15^{88}$ & 104 & .92 & $.06[.04 / .08]$ & .08 & - & - \\
\hline Measurement weights & $180.74^{* 8}$ & 113 & .92 & $.06[.04 / .07]$ & .08 & 9.60 & 9 \\
\hline Measurement intercepts & $188.98^{* 8}$ & 125 & .92 & $.05[.04 / .07]$ & .08 & 8.24 & 12 \\
\hline Structural weights & $189.07^{* 8}$ & 128 & .93 & $.05[.04 / .07]$ & .08 & 0.08 & 3 \\
\hline Structural covariances & $190.97^{* 8}$ & 129 & .92 & $.05[.04 / .07]$ & .08 & 1.91 & 1 \\
\hline
\end{tabular}

\section{DISCUSSION}

The present study is an innovative contribution on the processes explaining parents' adaptation outcomes in the challenging context of caring for a child with asthma. In summary, we found that caregiving uplifts were associated with parents' QoL outcomes, although only indirectly via positive reframing as a coping strategy. These findings were strengthened by ascertaining the invariance of this mediation model across different groups of parents who, due to their children's developmental stage and asthma clinical severity, have distinct caregiving demands. Taken together, our results support the pertinence of considering the positive dimensions of caregiving (e.g., uplifts) and meaning-making coping mechanisms for an improved understanding of parents' adaptation within a risk-resilience framework, namely the role of positive reappraisals in the context of stress processing mechanisms.

As stated in our hypothesis, parents' perception of benefits and gratifications arising from caring for a child with asthma was positively associated with their QoL, but only for the social 
domain. Complementary to the social support deterioration model, according to which chronic parenting stress may exhaust social resources and elicit inadequate responses from network members and, consequently, increase parents' maladjustment (Carona, Crespo, \& Canavarro, 2013), the distinctive association between parents' uplifts and social QoL may reflect the importance of positive emotions in establishing and maintaining supportive social relationships (Frederickson, 1998). In addition, parents of children with chronic health conditions or disabilities have similar social network structures to other families, but they may use their social resources differently in order to reappraise caregiving strains and improving their adaptation outcomes (Kazak, 1987). Further research is required to clarify the impact of social support on positive meaning-making coping strategies and parental adaptation outcomes in pediatric contexts.

However, when considering QoL as a multidimensional construct including physical, psychological, social and environmental domains, the beneficial effect of caregiving uplifts emerged only in an indirect way, via positive reframing coping, confirming our mediation hypothesis. Our findings support the applicability of the broaden-and-build model of positive emotions (Frederickson, 1998) in the developmental context of caring for a child with asthma. The experience of uplifts, which involves positive emotions related to caregiving, may facilitate the development of general positive coping dispositions, such as positive reframing (e.g., maintaining a positive look over life and its circumstances). In turn, positive meaningmaking reappraisals on caregiving demands have been stated as effective coping mechanisms to sustain the well-being of parents who have children with disabilities (Judge, 1998; Larson, 2010). Moreover, there is scarce but important evidence that parental coping patterns may also influence the psychological functioning and health-related QoL of their children with asthma (e.g., Sales, Fivush, \& Teague, 2008). Thus, future research should clarify the potential role of caregiving uplifts and positive meaning-making reappraisal on the transactional processes between children's and parents' adaptation.

Finally, we examined the mediation model's (in)variance across children's age groups and asthma severity levels but no significant differences on the strength of the aforementioned associations were found. Although important differences on parental adaptation outcomes may exist according to asthma severity levels (Everhart, Fiese, \& Smyth, 2008) and children's age groups (Carona, Pereira, et al., 2013), our findings suggested that the experience of caregiving uplifts may operate through similar mechanisms (i.e., via positive reframing coping) in both developmental and clinical groups. Thus, our study also adds preliminary evidence for the general applicability of this specific parental adaptation mechanism, regardless of their children's age group or asthma severity level, which may guide and facilitate parental psychological assessment and intervention in pediatric asthma settings.

The results from the present study should be read with caution due to some limitations in the study's design and procedures. The main limitation was the study's cross-sectional design, which prevents the establishment of causality among the variables. Although the directional paths tested in the mediation model have been hypothesized according to the literature, further longitudinal research should be undertaken to clarify the direction of these associations and to examine whether changes in the attribution of meanings to the caregiving experience may influence the parental adaptation processes over time. Our study was also limited by the nonprobabilistic sampling method and the consequent heterogeneous distribution of sample 
characteristics. The pediatric literature has advocated that the role of primary caregivers of children with chronic health conditions is commonly assumed by mothers, and that mothers are likely to be more vulnerable to psychological symptoms and lower QoL than fathers (Goldbeck, 2006; Silver, Westbrook, \& Stein, 1998). Consistently with these studies, our sample was mainly composed of mothers; however, the low frequency of fathers precluded the examination of the role of caregivers' gender on the mediating processes explaining parents' QoL. Furthermore, about a half of the parents had a child with intermittent asthma, which forced the dichotomization of the asthma severity variable. Although the distribution of children by asthma severity levels in our sample has been similar to the Portuguese pediatric population distribution (Gaspar, Almeida, \& Nunes, 2006), the increased variability within the persistent asthma group may have overlooked potential differences in the parameters tested in the mediation model according to asthma severity levels.

Despite these limitations, several implications for clinical practice and research can be drawn. The impact of childhood health conditions on the family and the reciprocal influences between parents' and their children's adaptation are extensively recognized in pediatric psychology (Sameroff, 2009). Therefore, clinical interventions in pediatric settings should be family-centered and consider parents' adaptation processes and outcomes. The assessment of positive dimensions of caregiving (e.g., uplifts) is essential to provide a comprehensive depiction of the caregiving experience and may contribute to operationalize a strength-based approach in promoting family adaptation. Therefore, encouraging parents' perception of caregiving gratifications and personal growth is an important target for interventions aiming at promoting coping strategies in adverse circumstances and long-term adaptation (Joseph \& Linley, 2006). Mindful-based interventions have already proven to be effective in reducing stress and anxiety and increasing personal growth in caregivers of children with special needs (Benn, Akiva, Arel, \& Roeser, 2012), which may then "broaden and build" their coping repertoires (Larson, 2010), and specifically meaning-based coping mechanisms such as positive reframing or reappraisal. However, applications of meaning-making coping models to promote parental positive adaptation in the context of pediatric asthma still need further research, particularly longitudinal studies and randomized controlled clinical trials. Moreover, future research should examine the mediating role of other specific meaning-based coping mechanisms, such as acceptance or self-compassion, on the associations between caregivingrelated emotions and parental adaptation, and also on the transactional processes between parental coping patterns and children's adaptation outcomes.

\section{REFERENCES}

Barlow, J. H., \& Ellard, D. R. (2006). The psychosocial well-being of children with chronic disease, their parents and siblings: An overview of the research evidence base. Child: Care, Health and Development, 32, 19-31. doi: 10.1111/j.1365-2214.2006.00591.x

Benn, R., Akiva, T., Arel, S., \& Roeser, R. W. (2012). Mindfulness training effects for parents and educators of children with special needs. Developmental Psychology, 48, 1476-1487. doi: 10.1037/a0027537 
Beresford, B. A. (1994). Resources and strategies: How parents cope with the care of a disabled child. Journal of Child Psychology and Psychiatry, 35, 171-209. doi: 10.1111/j.1469-7610.1994.tb01136.x

Browne, M., \& Cudeck, R. (1993). Alternative ways of assessing model fit. In K. Bollen \& J. Long (Eds.), Testing structural equation models (pp. 136-162). Newbury Park, CA: Sage Publications.

Canning, R. D., Harris, E. S., \& Kelleher, K. J. (1996). Factors predicting distress among caregivers to children with chronic medical conditions. Journal of Pediatric Psychology, 21, 735-749. doi: 10.1093/jpepsy/21.5.735

Carona, C., Crespo, C., \& Canavarro, M. C. (2013). Similarities amid the difference: Caregiving burden and adaptation outcomes in dyads of parents and their children with and without cerebral palsy. Research in Developmental Disabilities, 34, 882-893. doi: 10.1016/j.ridd.2012.12.004

Carona, C., Pereira, M., Moreira, H., Silva, N., \& Canavarro, M. C. (2013). The disability paradox revisited: Quality of life and family caregiving in pediatric cerebral palsy. Journal of Child and Family Studies, 22, 971-986. doi: 10.1007/s10826-012-9659-0

Carona, C., Silva, N., \& Canavarro, M. C. (2011, July). Avaliação de dimensões positivas e negativas da prestação de cuidados familiares: Estudos de validação da "Revised Burden Measure" em contextos pediátricos. In H. Moreira \& M. C. Canavarro (Chair), Avaliação da parentalidade: Construção e desenvolvimento de instrumentos de avaliação. Symposium conducted at the VIII Congresso Iberoamericano de Avaliação Psicológica/ XV Conferência Internacional Avaliação Psicológica: Formas e Contextos, Lisboa.

Carver, C. S. (1997). You want to measure coping but your protocol's too long: Consider the Brief COPE. International Journal of Behavioral Medicine, 4, 92-100. doi: 10.1207/s15327558ijbm0401_6

Carver, C. S., Scheier, M. F., \& Weintraub, J. K. (1989). Assessing coping strategies: A theoretically based approach. Journal of Personality \& Social Psychology, 56, 267-283. doi: 10.1037/0022-3514.56.2.267

Crespo, C., Carona, C., Silva, N., Canavarro, M. C., \& Dattilio, F. M. (2011). Understanding the quality of life for parents and their children who have asthma: Family resources and challenges. Contemporary Family Therapy, 33, 179-196. doi: 10.1007/s10591-0119155-5

Everhart, R. S., Fiese, B. H., \& Smyth, J. M. (2008). A cumulative risk model predicting caregiver quality of life in pediatric asthma. Journal of Pediatric Psychology, 33, 809818. doi: 10.1093/jpepsy/jsn028

Fiese, B. H., Wamboldt, F. S., \& Anbar, R. D. (2005). Family asthma management routines: Connections to medical adherence and quality of life. The Journal of Pediatrics, 146, 171-176. doi: 10.1016/j.jpeds.2004.08.083

Folkman, S. (1997). Positive psychological states and coping with severe stress. Social Science \& Medicine, 45, 1207-1221. doi: 10.1016/S0277-9536(97)00040-3

Folkman, S., \& Moskowitz, J. T. (2000). Stress, positive emotion, and coping. Current Directions in Psychological Science, 9, 115-118. doi: 10.1111/1467-8721.00073 
Fredrickson, B. L. (1998). What good are positive emotions? Review of General Psychology, 2, 300-319. doi: 10.1037/1089-2680.2.3.300

Garro, A. (2011). Coping patterns in Latino families of children with asthma. Journal of Pediatric Health Care, 25, 347-354. doi: 10.1016/j.pedhc.2010.04.005

Gaspar, A., Almeida, M. M., \& Nunes, C. (2006). Epidemiologia da asma grave. Revista Portuguesa de Imunoalergologia, 14, 27-41.

Gates, L. B., \& Akabas, S. H. (2012). Meeting the demands of work and responsibilities of caring for a child with asthma: Consequences for caregiver well-being. Journal of Social Service Research, 38, 656-671. doi: 10.1080/01488376.2012.709481

Global Initiative for Asthma. (2008). Global strategy for asthma management and prevention - updated 2008. Retrieved from http://www.ginasthma.org

Goldbeck, L. (2006). The impact of newly diagnosed chronic pediatric conditions on parental quality of life. Quality of Life Research, 15, 1121-1131. doi: 10.1007/s11136-006-0068y

Green, S. E. (2007). "We're tired, not sad": Benefits and burdens of mothering a child with a disability. Social Science \& Medicine, 64, 150-163. doi: 10.1016/j.socscimed.2006.08.025

Gupta, A., \& Singhal, N. (2004). Positive perceptions in parents of children with disabilities. Asia Pacific Disability Rehabilitation Journal, 15, 22-35.

Hair, J. F., Black, W. C., Babin, B. J., \& Anderson, R. E. (2010). Multivariate data analyses ( $7^{\text {th }}$ ed.). New Jersey: Prentice Hall.

Hu, L., \& Bentler, P. M. (1999). Cutoff criteria for fit indexes in covariance structure analysis: Conventional criteria versus new alternatives. Structural Equation Modeling: A Multidisciplinary Journal, 6, 1-55. doi: 10.1080/10705519909540118

Joseph, S., \& Linley, P. A. (2006). Growth following adversity: Theoretical perspectives and implications for clinical practice. Clinical Psychology Review, 26, 1041-1053. doi: 10.1016/j.cpr.2005.12.006

Judge, S. L. (1998). Parental coping strategies and strengths in families of young children with disabilities. Family Relations, 47, 263-268. doi: 10.2307/584976

Kazak, A. E. (1987). Families with disabled children: Stress and social networks in three samples. Journal of Abnormal Child Psychology, 15, 137-146. doi: 10.1007/BF00916471

Kline, R. B. (2005). Principles and practice of structural equation modeling (2nd ed.). New York, NY: The Guilford Press.

Larson, E. (2010). Psychological well-being and meaning-making when caregiving for children with disabilities: Growth through difficult times or sinking inward. OTJR: Occupation, Participation and Health, 30, 78-86. doi: 10.3928/15394492-20100325-03

Little, T. D. (Ed.). (2013). The Oxford handbook of quantitative methods in psychology (Vol. 1). New York, NY: Oxford University Press.

Montgomery, R., \& Kosloski, K. (2006). The league of experienced family caregivers: Measure development. Milwaukee, WI: University of Wisconsin-Milwaukee.

Pais-Ribeiro, J. L., \& Rodrigues, A. P. (2004). Questões acerca do coping: A propósito do estudo de adaptação do Brief Cope. Psicologia, Saúde \& Doenças, 5, 3-15. 
Preacher, K. J., \& Hayes, A. F. (2008). Asymptotic and resampling strategies for assessing and comparing indirect effects in multiple mediator models. Behavior Research Methods, 40, 879-891. doi: 10.3758/BRM.40.3.879

Sales, J., Fivush, R., \& Teague, G. W. (2008). The role of parental coping in children with asthma's psychological well-being and asthma-related quality of life. Journal of Pediatric Psychology, 33, 208-219. doi: 10.1093/jpepsy/jsm068

Sameroff, A. (Ed.). (2009). The transactional model of development: How children and contexts shape each other. Washington, DC: American Psychological Association.

Silver, E. J., Westbrook, L. E., \& Stein, R. (1998). Relationship of parental psychological distress to consequences of chronic health conditions in children. Journal of Pediatric Psychology, 23, 5-15. doi: 10.1093/jpepsy/23.1.5

Simões, M. R. (1994). Investigações no âmbito da aferição nacional do teste das Matrizes Progressivas de Raven. Unpublished Doctoral Dissertation. Universidade de Coimbra. Coimbra, Portugal.

The WHOQOL Group. (1998). Development of the World Health Organization WHOQOLBREF quality of life assessment. Psychological Medicine, 28, 551-558.

Vaz-Serra, A., Canavarro, M. C., Simões, M. R., Pereira, M., Gameiro, S., Quartilho, ..., Paredes, T. (2006). Estudos psicométricos do instrumento de avaliação da qualidade de vida da Organização Mundial de Saúde (WHOQOL-Bref) para português de Portugal. Psiquiatria Clínica, 27, 41-49.

Wallander, J. L, Varni, J. W., Babani, L., Banis, H. T., \& Wilcox, K. T. (1989). Family resources as resistance factors for psychological maladjustment in chronically ill and handicapped children. Journal of Pediatric Psychology, 14, 157-173. doi: 10.1093/jpepsy/14.2.157

Williams, J., \& MacKinnon, D. P. (2008). Resampling and distribution of the product methods for testing indirect effects in complex models. Structural Equation Modeling, 15, 23-51. doi: 10.1080/10705510701758166

\section{Acknowledgements}

This study was supported by the R\&D Unit Institute of Cognitive Psychology, Vocational and Social Development of the University of Coimbra (PEst-OE/PSI/UI0192/2011); and by the Portuguese Foundation for Science and Technology (PhD Grant SFRH/BD/69885/2010). 